\title{
Analysis of trihalomethanes in water and air from indoor swimming pools using HS-SPME/GC/ECD
}

\author{
CHRISTOPHER S. A. SÁ, RUI A. R. BOAVENTURA and ISABEL B. PEREIRA
}

Headspace solid phase microextraction (HS-SPME) with further quantification by gas chromatography and electron capture detector (GC/ECD) was used to analyze trihalomethanes (THMs) in water and air from indoor swimming pools (ISPs). High correlation coefficients were obtained for the calibration lines in water with detection limits of $0.2 \mu \mathrm{g} / \mathrm{L}$ for trichloromethane (TCM) and bromodichloromethane (BDCM), $0.1 \mu \mathrm{g} / \mathrm{L}$ for dibromochloromethane (DBCM) and $0.5 \mu \mathrm{g} / \mathrm{L}$ for tribromomethane (TBM). Coefficients of variation values were $5-10 \%$ for repeatability and $15-25 \%$ for reproducibility. In air analysis, high correlation coefficients were also obtained for the calibration lines with detection limits of $2.5 \mu \mathrm{g} / \mathrm{m}^{3}$ for TCM and BDCM and $1.25 \mu \mathrm{g} / \mathrm{m}^{3}$ for DBCM and TBM. Repeatability and reproducibility coefficients of variation were the same as in water analysis. Analytical results from a survey in four Portuguese ISPs showed that the mean concentration of total trihalomethanes (TTHMs) in water ranged from $22 \pm 2$ to $577 \pm 58 \mu \mathrm{g} / \mathrm{L}$. In the lack of European specific regulation for THMs in water from ISPs and taking into consideration that ingestion is a form of exposure, TTHMs' values were compared with European drinking water maximum contamination level $(100 \mu \mathrm{g} / \mathrm{L}$, Directive 98/83/CE). From the reported TTHMs mean concentration values in ISPs' water, 40\% exceeded that value. TTHMs values determined in the air $\left(\mathrm{T}=30^{\circ} \mathrm{C}\right)$ ranged from $98 \pm 10$ to $1225 \pm 123 \mu \mathrm{g} / \mathrm{m}^{3}$ and from $51 \pm 5 \mu \mathrm{g} / \mathrm{m}^{3}$ to $519 \pm 52 \mu \mathrm{g} / \mathrm{m}^{3}$ at 5 and $150 \mathrm{~cm}$ above the water surface, respectively. As expected, swimmers are more exposed to high concentrations of THMs than lifeguards. As there is no European specific regulation for THMs in ISPs' air, the highest TCM values were compared with maximum values reported in the literature for ISPs $\left(1630 \mu \mathrm{g} / \mathrm{m}^{3}\right)$ and with the inhalation exposure limit $\left(10,000 \mu \mathrm{g} / \mathrm{m}^{3}\right)$ established for TCM by European occupational legislation (Directive 2000/39/CE).

Keywords: Trihalomethanes, air, water, indoor swimming pools, HS-SPME/GC/ECD.

\section{Introduction}

Chlorine is widely used as water disinfectant with the advantage of preventing microorganisms' regrowth if residual concentrations are guaranteed. However, it reacts with natural organic matter in the raw water via halogen substitution and oxidation reactions, forming a wide range of compounds known as disinfection by-products (DBPs). ${ }^{[1]}$ Typically, the most common DBPs are trihalomethanes (THMs), ${ }^{[2]}$ which are a group of compounds that include chloroform or trichloromethane (TCM; $\mathrm{CHCl}_{3}$ ), bromodichloromethane (BDCM; $\mathrm{CHBrCl}_{2}$ ), dibromochloromethane ( $\left.\mathrm{DBCM} ; \mathrm{CHBr}_{2} \mathrm{Cl}\right)$ and bromoform or tribromomethane (TBM; $\left.\mathrm{CHBr}_{3}\right)$.
Toxicological studies carried out with chloroform and other THMs indicate that they may have detrimental effects on human health. ${ }^{[3]}$ THMs have been referred to as probable or potential carcinogens because of tumour induction in one or more animal species. ${ }^{[2,3]}$ IARC (International Agency for Research Cancer) in 1987 and 1991, respectively, classifies TCM and BDCM as carcinogens type 2B (possible carcinogens). In 1986 US EPA assigns TCM as a carcinogen type B2 (probable carcinogen) and in 1998 states that it is likely to be carcinogenic to humans by all routes of exposure under high-dose conditions that lead to cytotoxicity and regenerative hyperplasia in susceptible tissues. The adverse health implications of THMs have prompted a requirement for the establishment of legal limits. A maximum contamination level (MCL) of $100 \mu \mathrm{g} / \mathrm{L}$ for TTHMs in drinking water was recommended by the U.S. Environmental Protection Agency (1983) and $30 \mu \mathrm{g} / \mathrm{L}$ of chloroform fixed as the permissible level for drinking water ${ }^{[2]} \mathrm{In}$ 1998, US EPA has set MCL for TTHMs at $80 \mu \mathrm{g} / \mathrm{L}$, but in Europe this limit is still fixed in $100 \mu \mathrm{g} / \mathrm{L}$. 
THMs exist in swimming pool waters when there is addition of chlorine as disinfectant, and it reacts with organic matter. Perspiration, urine, hair, saliva, cosmetics are some of the possible sources of that organic matter. ${ }^{[4]}$ TCM has been the most frequently analysed THMs and reported values in a range of 0.5 to $980 \mu \mathrm{g} / \mathrm{L}$ were found in the literature. ${ }^{[2,4,18]}$ The presence of chloroform in the atmosphere of indoor swimming pools (ISPs) has also been reported by several authors $[2,5,7,9-12,14-20]$ with concentration values ranging from 1.7 to $1630 \mu \mathrm{g} / \mathrm{m}^{3}$. Differences in ventilation rates and in disinfection practices are two possible explanations for this wide ranges of chloroform concentrations in water and air.

Ingestion and inhalation together with skin absorption are the three types of exposure of a person in an ISP. Taking into consideration that it may be necessary at least one night for an adult to excrete the absorbed mean quantities of THMs ${ }^{[5]}$ it is possible to say that, if insufficient time elapses between training sessions, a scenario of toxic buildup can become real.

The European Community has not yet established specific legislation for THMs in air and water of ISPs. For this reason and as ingestion is one of exposure forms in those environments, the parametric value for THMs in drinking water $(100 \mu \mathrm{g} / \mathrm{L}$, in Europe) has been often used as an indicative reference value for THMs concentration evaluation in water from swimming pools. However, a few countries individually have already fixed a maximum value for TTHMs in water of swimming pools, as is the case of Germany in compliance with DIN $19643\left(20 \mu \mathrm{g} / \mathrm{L}^{[21]}\right)$ and Denmark $\left(50 \mu \mathrm{g} / \mathrm{L}^{[22]}\right)$.

The above-reported ranges of THMs in water of swimming pools clearly show that a great effort should be made if the German limit would apply. No matter which value will be fixed by European legislation, it may be expected that this will occur in a short term, and an improvement will be required in monitoring and assessment of DBPs in air and water from ISPs. So, the availability and development of expeditious and reliable analytical methods are of the utmost importance in this field.

Solid phase microextraction (SPME) has been successfully applied to the extraction of volatile organic compounds (VOCs) and other organic compounds from water, soils and air samples. ${ }^{[23-27]}$ SPME is a fast, sensitive, inexpensive, portable and solvent-free method. The concept is the partition of sample analytes between water and air and extraction with sorption of analytes onto a polymeric coating in a fused silica fiber. When sample matrix is complex headspace technique (HS) is an interesting option as it can provide higher enrichment of selected volatile compounds. After extraction, analytes' desorption is done on the injection port of a gas chromatograph (GC). The detectors most widely used in the analyses of THMs are mass spectrometer (MS) and electron capture detector (ECD). ${ }^{[28]} \mathrm{HS}$ together with SPME (HS-SPME) has already been applied to THMs analysis in drinking water ${ }^{[25,29,30]}$ and swimming pool water ${ }^{[31,32]}$ In these works the detection was done by GC/ECD ${ }^{[25,29,30]}$ and by GC/MS. ${ }^{[31,32]}$ These detectors have also been used in the quantification of THMs in the air of ISPs. ${ }^{[33-35]}$ In these reports the sampling technique included sorbent tubes and thermal desorption.

The aim of this study was to evaluate THMs contents in water and air from indoor swimming pools using HSSPME/GC/ECD. The analysis of THMs in air from ISPs using SPME represents a new approach among the sampling techniques already reported in the literature. Furthermore adopting a very similar procedure for water and air samples' characterization is important when time and labour are relevant in analytical programmes. The obtained data for THMs' levels in four ISPs may be useful for toxicologists and rulers.

\section{Materials and methods}

The experimental conditions were established to obtain high efficiency in the extraction step and HS-SPME parameters were optimised to achieve good sensitivity in the GC/ECD analysis. The optimised procedure was applied to the determination of THMs - trichloromethane (TCM), bromodichloromethane (BDCM), dibromochloromethane (DBCM) and tribromomethane (TBM) - in water and air from indoor swimming pools.

\section{Chemicals and materials}

THMs individual standards with the references $48520-\mathrm{U}$, 48540-U, 48542 and 48539 were purchased from Supelco (Bellefonte, PA). A commercially THMs mixture in acetone $\left(\mathrm{CHCl}_{3}, \mathrm{CHCl}_{2} \mathrm{Br}, \mathrm{CHClBr} 2\right.$ and $\left.\mathrm{CHBr}_{3}\right)$ containing $2000 \mu \mathrm{g} / \mathrm{mL}$ of each compound (EPA 551A Halogenated Volatiles Mix) was also purchased from Supelco. This mixture as well as the individual standards were handled in accordance with material safety data sheets.

Screw-capped vials ( 4 and $40 \mathrm{~mL}$ ), sealed with a Teflonlined silicon septum were used for storing the standard solutions as well as for water and air samples. The vials were cleaned using an alkaline soap solution for $24 \mathrm{~h}$ and then rinsed in deionised water, acetone (Pronolab), again in deionised water and finally in ultrapure type I deionized water (Barnstead purification system). Afterwards they were muffled at $400^{\circ} \mathrm{C}$ for $30 \mathrm{~min}$. Glassware was also washed as described above and dried at $45^{\circ} \mathrm{C}$.

In this study two types of fibers, $100 \mu \mathrm{m}$ polydimethylsiloxane (100-PDMS) and $75 \mu \mathrm{m}$ Carboxen/ polydimethylsiloxane (75-CAR/PDMS), both supplied by Supelco, were chosen to perform HS-SPME for analysing THMs in water and air, respectively. The 100PDMS fiber was selected after previous tests with different coatings ( $60 \mu \mathrm{m}$ polydimethylsiloxane/divinylbenzene, $85 \mu \mathrm{m}$ polyacrylate and $100 \mu \mathrm{m}$ polydimethylsiloxane). To 
achieve lower detection limits (mass/volume) needed for air analysis, a CAR/PDMS fiber was used.

\section{THMs analysis in water}

\section{Preparation of THMs standards for water analysis}

Intermediate standard solutions of THMs with 1 and 2 $\mathrm{mg} / \mathrm{L}$ were obtained by diluting the THMs mixture standard solution $(2000 \mu \mathrm{g} / \mathrm{mL}$ in each THM) with acetone (Pronolab). These intermediate stock solutions were prepared weekly, and then frozen in the dark at $-18^{\circ} \mathrm{C}$ until use. Stock calibration standard solutions, in the range $0.5-19.5 \mu \mathrm{g} / \mathrm{L}$, were prepared for calibration by diluting the intermediate stock solutions with ultrapure type I water directly into $4 \mathrm{~mL}$ vials (from Supelco). All standards were analyzed in triplicate at $55 \pm 1{ }^{\circ} \mathrm{C}$. A chromatogram of a standard mixture of 4 THMs in water is presented in Figure 1(c).

\section{Temperature, stirring rate and time of extraction}

Some preliminary experiments were performed varying the extraction times between 1 and $40 \mathrm{~min}$. Equilibrium conditions for every compound were reached after $40 \mathrm{~min}$. From $10 \mathrm{~min}$ to $40 \mathrm{~min}$ the increase in peak area was only $10 \%$ (from 90 to $100 \%$ of maximum peak area) so a time of 10 minutes was established for fiber contact to save analysis time. Results were identical for all THMs.

Different water stirring rates were also tested for extraction step confirming a proportional increase in THMs recovery with stirring rate. However values higher than $300 \mathrm{rpm}$ caused water splashes thrown into the fiber, which interfered with subsequent analysis. When samples were stirred at $300 \mathrm{rpm}$, recoveries of TCM, BDCM, DBCM, and TBM were 2.0, 2.5, 2.7 and 2.7 times better than those at static conditions. That stirring rate value was used for further analysis.

To validate the effect of temperature on the extraction efficiency some experiments were performed at temperatures between 30 and $65^{\circ} \mathrm{C}$. The temperature of $55^{\circ} \mathrm{C}$ was the

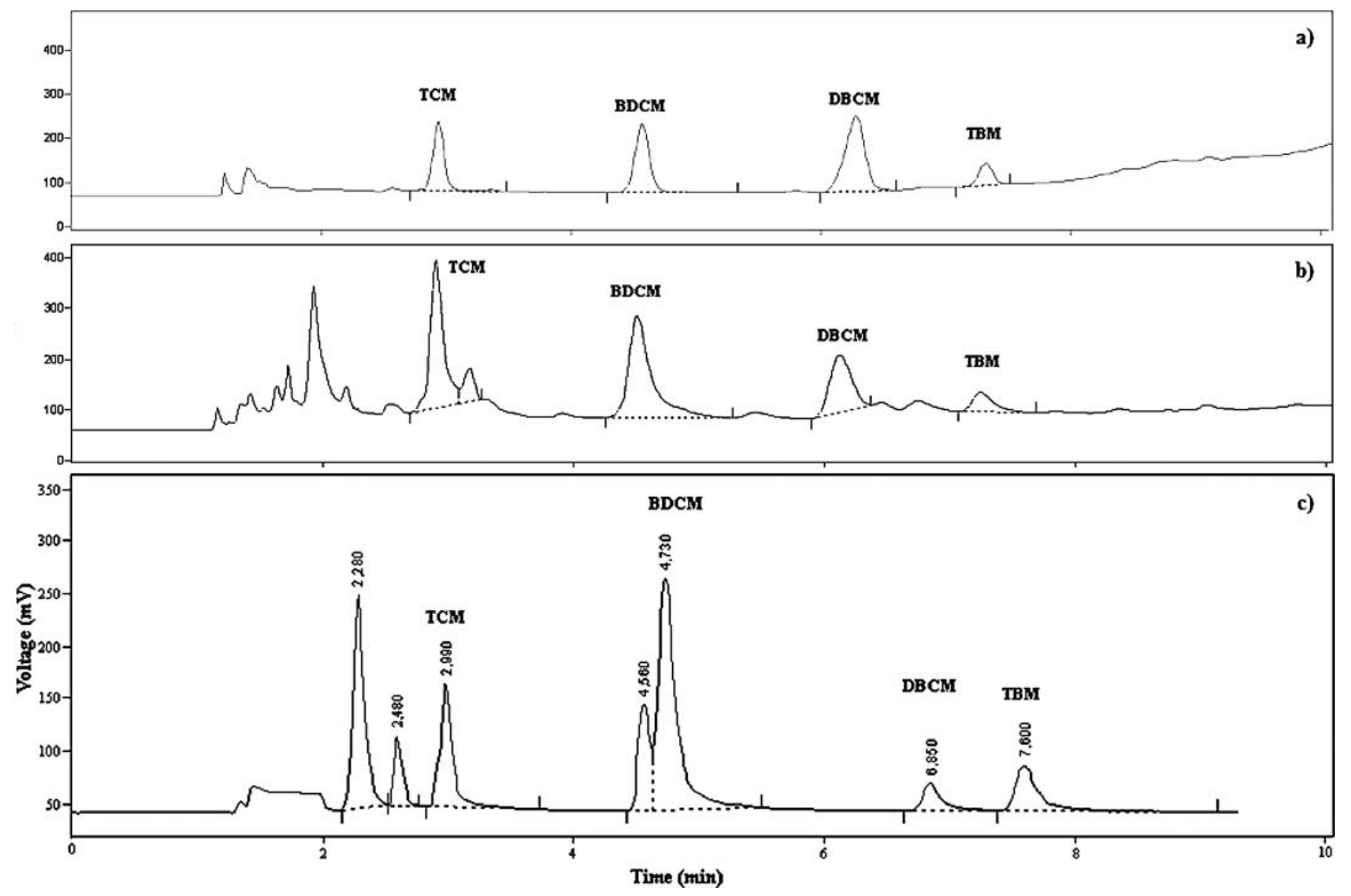

Fig. 1. GC chromatograms: (a) water sample from MC swimming pool, (b) air sample from MC swimming pool, bottom, and (c) standard mixture with concentrations of $0.5 \mu \mathrm{g} / \mathrm{L}$. 
optimum value and used for further analysis. Higher temperatures may have the negative effect of less favourable coating-headspace (air) partition coefficients. ${ }^{[29]}$

\section{Procedure for HS-SPME of water samples}

Several preliminary tests were performed in order to study every variable of the analytical system and possible interferences from volatile materials in air lab, glassware, reagents, septa, fiber glue and purge gas were identified and kept under control.

The 100-PDMS fiber was conditioned at $300^{\circ} \mathrm{C}$ for $1 \mathrm{~h}$ prior to use and a blank desorption was performed. A small volume of water sample $(1.6 \mathrm{~mL})$ was transferred into a vial (4 mL, Supelco), so the headspace volume was $2.4 \mathrm{~mL}$. This volume was chosen taking into account the fiber height and SPME theory which enunciates that for high-sensitivity head-space extraction, the volume of gaseous phase should be minimised. The syringe assembly unit was lowered into the vial with the fiber suspended in the headspace above the agitated (with a magnetic stirring bar) liquid layer of the sample. The extraction lasted $10 \mathrm{~min}$ at $55 \pm 1{ }^{\circ} \mathrm{C}$ and then the fiber was immediately retracted back into the needle and transferred without delay to the injection port of the gas chromatograph, at $200^{\circ} \mathrm{C}$.

As the total chromatograph analysis of a sample took 18 min (see Gas Chromatographic System and Conditions section) and more $2 \mathrm{~min}$ were necessary for lowering the oven temperature to $80^{\circ} \mathrm{C}$, the needle (containing the fiber) was kept in the injection port during $10 \mathrm{~min}$. After that the fiber was immediately positioned in another vial, for another $10 \mathrm{~min}$ sample extraction. This procedure allowed the complete desorption of the THMs and prevented the adsorption of other compounds from surrounding air by the hot fiber which would interfere with subsequent chromatographic analysis.

Each water sample was analysed in duplicate and quantification of the four analytes was performed using the peak area calibration method. During all analytical campaigns blank and spiked samples analysis were carried through. A chromatogram of a water sample from MC swimming pool is presented in Figure 1(a).

\section{Water sampling}

Water samples from each of four municipal indoor swimming pools (ISPs) located in Northern Portugal were collected in five different days over 6 months. All the swimming pools are $25 \mathrm{~m}$ length and $12.5 \mathrm{~m}$ wide sportive tanks with similar water treatment and disinfection systems. Sodium hypochlorite was used as disinfection agent. Water was sampled at four different points of the pool (at the corners, $1 \mathrm{~m}$ away from the sides and at $20 \mathrm{~cm}$ depth) and immediately transported in an isothermal container to the laboratory for analysis. A dechlorant agent was not used since elapsed time between sampling and analysis beginning was less than 2 hours. Samples were collected to $40 \mathrm{~mL}$ amber glass bottles with PTFE-faced septa and polypropylene screw caps, avoiding the presence of headspace at the top.

\section{THMs analysis in air}

\section{Preparation of THMs standards for air analysis}

Standard stock solutions of THMs with intermediate concentrations of 10 and $1000 \mu \mathrm{g} / \mathrm{L}$ were obtained by diluting the mixture standard solution ( $2000 \mu \mathrm{g} / \mathrm{mL}$ in each THM) with acetone (Pronolab). Eight calibration standards, in the range $1.25-1250 \mu \mathrm{g} / \mathrm{m}^{3}$, were prepared using two Hamilton syringes of $5 \mu \mathrm{L}$ (ref. 87900) and $50 \mu \mathrm{L}$ (ref. 80500).

Small volumes $(5,15,25$ or $50 \mu \mathrm{L})$ of the intermediate solutions were injected into $40 \mathrm{~mL}$ vials, by septum perforation. After $1 \mathrm{~min}$ vaporisation of the liquid injected into each vial, the SPME fiber was exposed to the vapour for extraction at $30 \pm 1^{\circ} \mathrm{C}$. All standards were processed in triplicate.

\section{SPME choice for air samples analysis}

Two SPME fibers (100-PDMS and 75-CAR/PDMS) were tested to analyse THMs in air. Higher extraction efficiencies were obtained with 75-CAR/PDMS. Figure 2 shows the relative responses for the two fibers. The peak areas for 75-CAR/PDMS fiber were 14, 10, 10 and 9 times greater for TCM, BDCM, DBCM and TBM, respectively. So, this fiber was selected for further analysis.

\section{Temperature and time of extraction}

As an air temperature of $30 \pm 2^{\circ} \mathrm{C}$ is normal inside an indoor swimming pool, the temperature of $30 \pm 1{ }^{\circ} \mathrm{C}$ was established for the extraction of THMs from air samples. The authors had also in mind the future possibility of performing the HS-SPME technique directly in the swimming pool. Some extraction trials were carried out with a $125 \mu \mathrm{g} / \mathrm{m}^{3}$ THMs mixture standard and it was observed

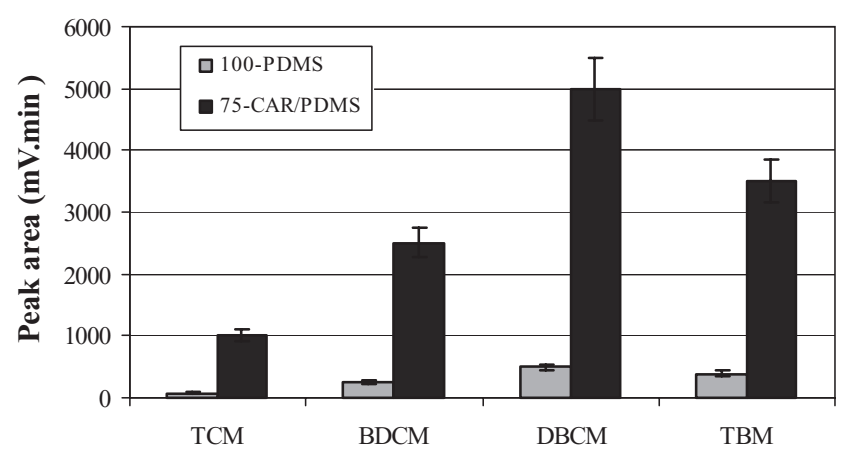

Fig. 2. Peak areas comparison of THM standards $\left(125 \mu \mathrm{g} / \mathrm{m}^{3}\right.$ air) for two SPME fibers. 
that 50 minutes were needed to achieve around 90\% (88\%) of the maximum peak chromatographic area which was already the criteria used for water samples analysis.

\section{Procedure for HS-SPME of air samples}

The 75-CAR/PDMS fiber was conditioned for $1 \mathrm{~h}$ prior to use. It was then lowered into the $40 \mathrm{~mL}$ vial and exposed to the air contained in the vial for $50 \mathrm{~min}$, at $30 \pm 1^{\circ} \mathrm{C}$. A blank desorption was always performed initially. After extraction, the fiber was immediately retracted back into the needle and transferred without delay to the injection port of gas chromatograph, at $200^{\circ} \mathrm{C}$. The following procedure was the same as described above in Procedure for HS-SPME of water samples. Identically, the possible interferences were kept under control as already referred in that subsection. A chromatogram of an air sample from MC swimming pool is presented in Figure 1(b).

Each air sample was analysed in duplicate and quantification of the four analytes was performed using the peak area calibration method. During all analytical campaigns fortified samples analysis was also done.

\section{Air sampling}

Air samples were collected in the same 4 municipal indoor swimming pools, at the same dates of water sampling. Air sampling was made at one corner of the swimming pool, $10 \mathrm{~cm}$ away from the two walls, 5 and $150 \mathrm{~cm}$ above water surface. The air was vacuum pumped at a flow rate of $1 \mathrm{~L} / \mathrm{min}( \pm 5 \%)$ into a $40 \mathrm{~mL}$ glass vial through a system of two needles that perforated the septum cap. After at least 1 minute, pump was switched off, both needles were removed simultaneously and septum cap immediately sealed. Samples were transported in an isothermal bag to laboratory for analysis.

\section{Gas chromatographic system and conditions}

Separations were carried out on a Dani 1100 gas chromatograph equipped with a $\mathrm{Ni}^{63}$ electron capture detector (ECD). The analytical column was a $30 \mathrm{~m}$ length, $0.53 \mathrm{~mm}$ i.d. and $3.0 \mu \mathrm{m}$ thickness ValcoBond VB-624, bonded and cross-linked with $6 \%$.

Cyanopropyl-phenyl)-methylpolysiloxane. Nitrogen was used as carrier gas $(5.8 \mathrm{~mL} / \mathrm{min}$ at a linear velocity of $40 \mathrm{~cm} / \mathrm{s})$ and as auxiliary gas $(1.1 \mathrm{~mL} / \mathrm{min})$. The oven was held at $80^{\circ} \mathrm{C}$ for $5 \mathrm{~min}$, then was ramped at $10^{\circ} \mathrm{C} / \mathrm{min}$ to $150^{\circ} \mathrm{C}$ and held for $6 \mathrm{~min}$ (total time $18 \mathrm{~min}$ ). Injection port and detector temperatures were set at $200^{\circ} \mathrm{C}$ (splitless) and $300^{\circ} \mathrm{C}$, respectively.

\section{Results and discussion}

\section{THMs in water}

Linearity, reproducibility and repeatability. The linearity range of the HS-SPME method was determined by plotting chromatographic peak areas versus concentration of each analyte. Standard calibration lines were drawn for concentrations ranging from 0.5 to $19.5 \mu \mathrm{g} / \mathrm{L}(\mathrm{n}=8)$. The correlation coefficients obtained for TCM, BDCM, DBCM and TBM were 0.9982, 0.9988, 0.9997 and 0.9964, respectively. To validate the calibration lines, a condition referred by Sousa ${ }^{[36]}$ was assumed: $S_{b} / b \leq 5 \%$, where $S_{b}$ is the standard deviation of the calibration line slope and $b$ is the calibration line slope. Values of $S_{b} / b$ obtained from the four calibration lines were equal to $1.8,1.4,0.7$ and $2.5 \%$, all of them smaller than 5\% and thus method was validated. Limits of detection for THMs considering the peaks with a signal-to-noise $(\mathrm{S} / \mathrm{N})$ ratio of $3: 1$ were $0.2 \mu \mathrm{g} / \mathrm{L}$ for TCM and BDCM, $0.1 \mu \mathrm{g} / \mathrm{L}$ for DBCM and $0.5 \mu \mathrm{g} / \mathrm{L}$ for TBM.

Repeatability was assessed by analysing 12 times the same THMs' mixture standard $(2.5 \mu \mathrm{g} / \mathrm{L})$ and the values of the coefficient of variation $(\mathrm{CV})$, defined as the ratio of standard deviation by mean, were $7.4,5.5,5.0$ and $10.0 \%$, for TCM, BDCM, DBCM and TBM, respectively. Reproducibility was also evaluated by injecting the same standard mixture once a day in 12 consecutive days. Coefficients of variation were $22.8,16.1,15.0$ and $25.0 \%$, which allowed concluding that GC/ECD has significant variations. Therefore, it was decided to verify the calibration line every day or every time a determination was performed.

\section{THMs in water samples from indoor swimming pools}

Eighty water samples from four public swimming pools (identified as F, MC, MSMF, and MPL) were collected and analysed in duplicate using the optimised HSSPME/GC/ECD method. The TTHMs concentration values obtained for each swimming pool are presented in Figure 3, ranging from $22 \pm 2$ to $577 \pm 58 \mu \mathrm{g} / \mathrm{L}$. Each value corresponds to the mean concentration of the four water samples collected in that swimming pool, in each day.

Portuguese and European legislation do not establish limits for the presence of THMs in swimming pool water. Taking into consideration that ingestion is an important route of exposure, TTHMs results were compared with the maximum parametric values established by the US EPA $(80 \mu \mathrm{g} / \mathrm{L}$ ) and EU legislation (Directive 98/83/CE) for drinking water $(100 \mu \mathrm{g} / \mathrm{L})$. The results showed that $50 \%$ of the water samples exceeded $80 \mu \mathrm{g} / \mathrm{L}$ and $40 \%$ surpassed $100 \mu \mathrm{g} / \mathrm{L}$.

The highest TTHMs values (close to $580 \mu \mathrm{g} / \mathrm{L}$ ) were found at MSMF, where the highest organic matter values were quantified. The mean TOC values determined in the 4 swimming pools' waters were $6.72 \pm 0.05 \mathrm{mg} / \mathrm{L}$ (MSMF), 


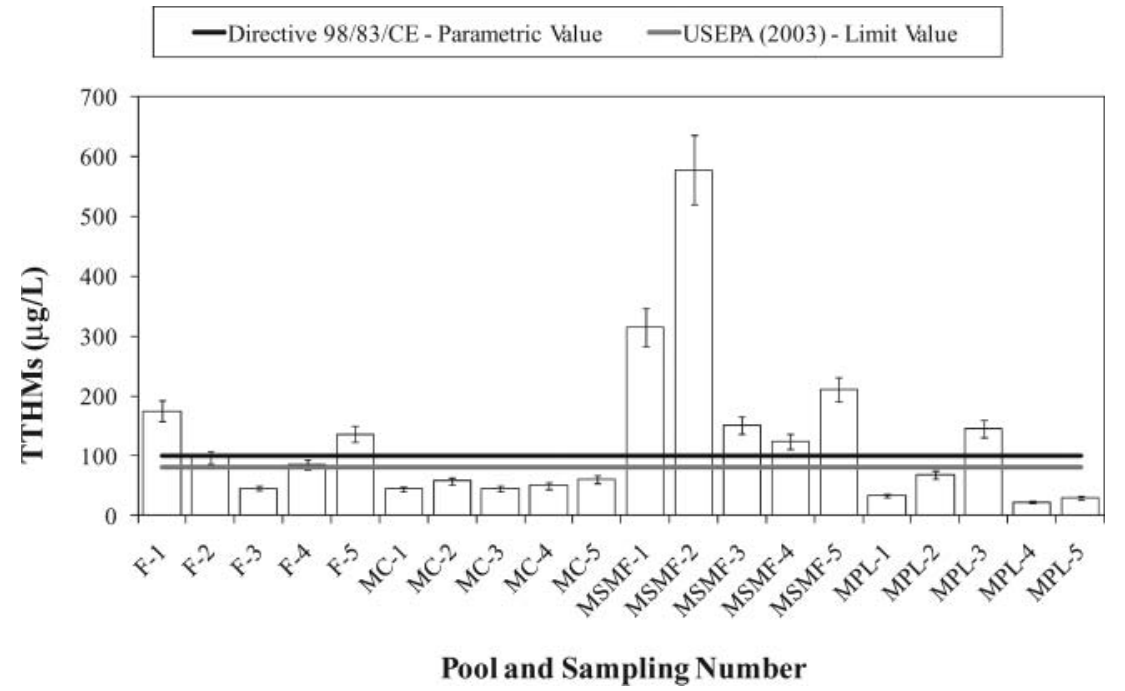

Fig. 3. Mean TTHMs values obtained in water from 4 indoor swimming pools, on 5 different days.

$4.34 \pm 0.24 \mathrm{mg} / \mathrm{L}$ (MC), $3.66 \pm 0.08 \mathrm{mg} / \mathrm{L}$ (F) and $1.13 \pm$ $0.06 \mathrm{mg} / \mathrm{L}$ (MPL). Moreover, the analysis of feed water in these pools showed permanganate oxidability mean values of $3.0 \mathrm{mgO}_{2} / \mathrm{L}$ in MSMF (drawn from an artesian well), $0.4 \mathrm{mg} \mathrm{O}_{2} / \mathrm{L}$ in MPL and $1.1 \mathrm{mg} \mathrm{O}_{2} / \mathrm{L}$ in both $\mathrm{F}$ and MC.

According to Evans et al. ${ }^{[2]}$ and their estimations of water involuntarily swallowed by swimmers (child, $0.090 \mathrm{~L}$, adult, $0.022 \mathrm{~L}$, athlete, $0.056 \mathrm{~L}$ - mean value between child and adult ingestion), THMs concentrations found in the pools and volume of water usually consumed during a normal day ( $1 \mathrm{~L}$ for children, $2 \mathrm{~L}$ for adults), it is possible to say that the ingested quantities of THMs per se might not be harmful to users health.

The TCM mean concentrations determined in water samples are presented in Figure 4. The values found, $18 \pm$ $2 \mu \mathrm{g} / \mathrm{L}$ to $520 \pm 52 \mu \mathrm{g} / \mathrm{L}$, represent $81 \pm 8 \%$ of the corresponding TTHMs mean concentration. The highest value obtained in this study (from MSMF) is $41 \%$ below the maximum value of $980 \mu \mathrm{g} / \mathrm{L}$ found in the literature for swimming pools. ${ }^{[18]}$

\section{THMs in air}

\section{Linearity, reproducibility and repeatability study}

The linearity range of the HS-SPME method was evaluated by plotting calibration lines for concentrations ranging between 1.25 and $1250 \mu \mathrm{g} / \mathrm{m}^{3}(\mathrm{n}=8)$. In this range the correlation coefficients obtained for TCM, BDCM, DBCM and TBM were $0.9979,0.9921,0.9977$ and 0.9937 , respectively. To validate the calibration lines, the same condition ${ }^{[36]}$ as for water samples was adopted. $S_{b} / b$ values obtained from the four calibration lines were equal to $1.9,3.7,2.0$ and $3.3 \%$. All these values are below 5\% and so the calibration lines were validated. Limits of detection considering

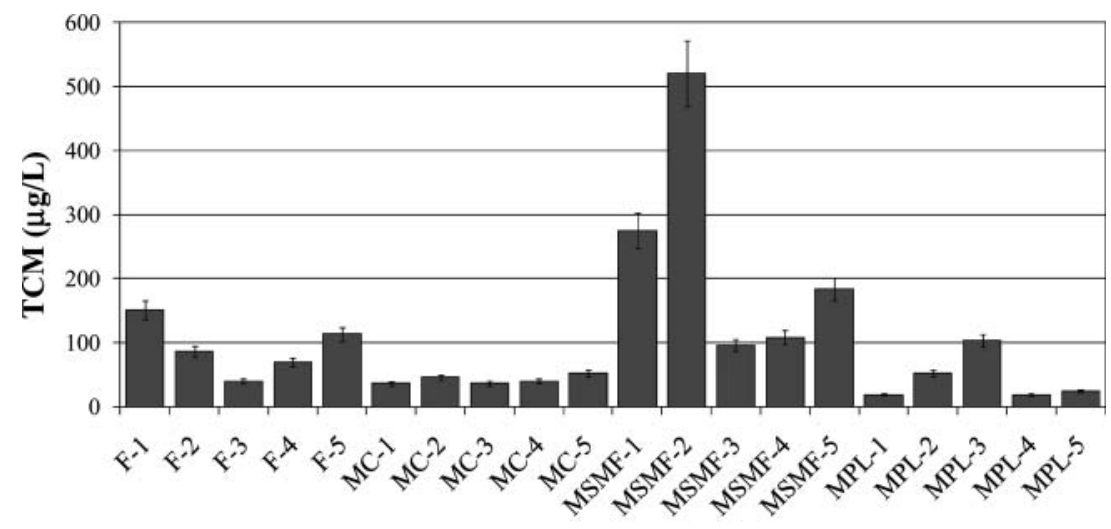

Pool and Sampling Number

Fig. 4. Mean TCM concentrations obtained in water from 4 indoor swimming pools, on 5 different days. 


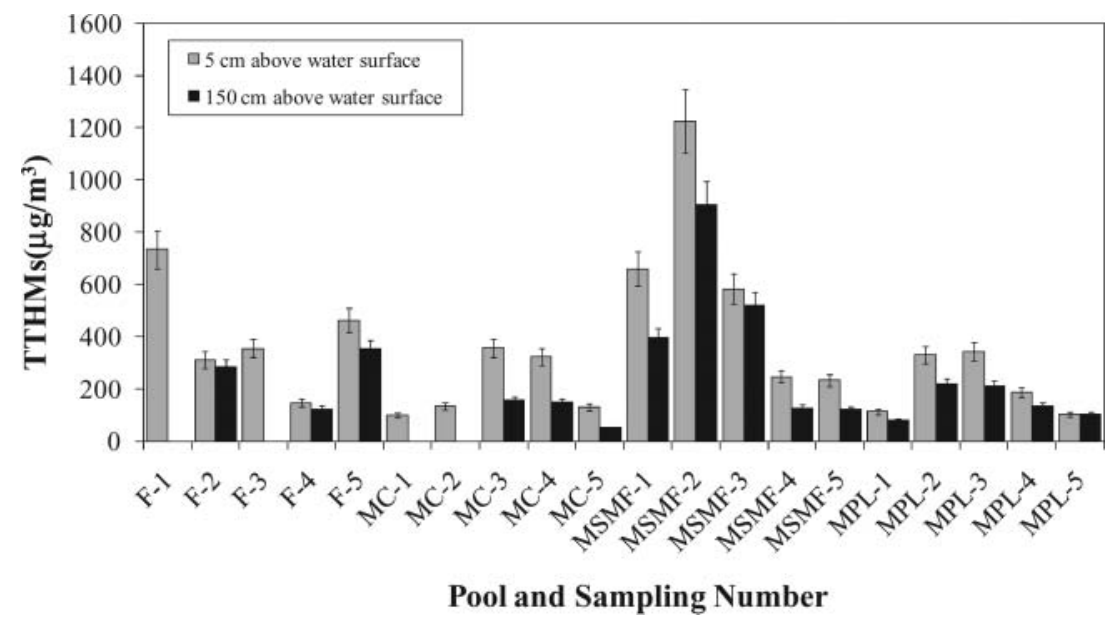

Fig. 5. Mean TTHMs values obtained in air samples collected at 150 and $5 \mathrm{~cm}$ above water surface in 4 indoor swimming pools, on 5 different days.

the peaks with a signal-to-noise $(\mathrm{S} / \mathrm{N})$ ratio of $2: 1$ were $2.5 \mu \mathrm{g} / \mathrm{m}^{3}$ (TCM), $2.5 \mu \mathrm{g} / \mathrm{m}^{3}$ (BDCM), $1.25 \mu \mathrm{g} / \mathrm{m}^{3}$ (DBCM) and $1.25 \mu \mathrm{g} / \mathrm{m}^{3}$ (TBM).

Repeatability was assessed by analysing 12 times a $125 \mu \mathrm{g} / \mathrm{m}^{3}$ standard. The coefficients of variation were 5.0 , 10.0, 5.3 and $8.8 \%$, for TCM, BDCM, DBCM and TBM, respectively. Reproducibility was also evaluated and coefficients of variation were 15.0, 25.0, 15.6, 23.1\% for TCM, BDCM, DBCM and TBM, respectively. Therefore, it was decided to verify the calibration line every day or every time a determination was performed.

\section{THMs in air samples from indoor swimming pools}

A total of 36 air samples from four public swimming pools (identified as F, MC, MSMF, and MPL) were analysed in duplicate using the optimised HS-SPME/GC/ECD method. The results obtained for TTHMs concentrations in the air of the swimming pools $(5 \mathrm{~cm}$ and $150 \mathrm{~cm}$ above water surface) are shown in Figure 5. Values of TTHMs concentrations at $150 \mathrm{~cm}$ above water surface ranged from $51 \pm 5$ to $906 \pm 91 \mu \mathrm{g} / \mathrm{m}^{3}$ and are $33 \pm 16 \%$ lower than the corresponding values found at $5 \mathrm{~cm}$. These data confirm that swimmers are exposed to higher concentrations of THMs by inhalation than lifeguards. In the lack of legal limits (national or European) for TTHMs in the atmosphere of indoor swimming pools TTHMs concentration values in the air of the studied swimming pools were compared with the maximum value of $1630 \mu \mathrm{g} / \mathrm{m}^{3}$ found in the literature ${ }^{[18]}$ for TCM in ISPs' air.

Individual results for TCM concentration in the air of the swimming pools at $5 \mathrm{~cm}$ above water surface are plotted in Figure 6. The highest value $\left(1004 \pm 100 \mu \mathrm{g} / \mathrm{m}^{3}\right)$ is lower than the maximum value found in literature (1630 $\left.\mu \mathrm{g} / \mathrm{m}^{3},[18]\right)$, and is considerably lower than the inhalation exposure limit of $10,000 \mu \mathrm{g} / \mathrm{m}^{3}$ established by European occupational legislation (Directive 2000/39/CE), OSHA

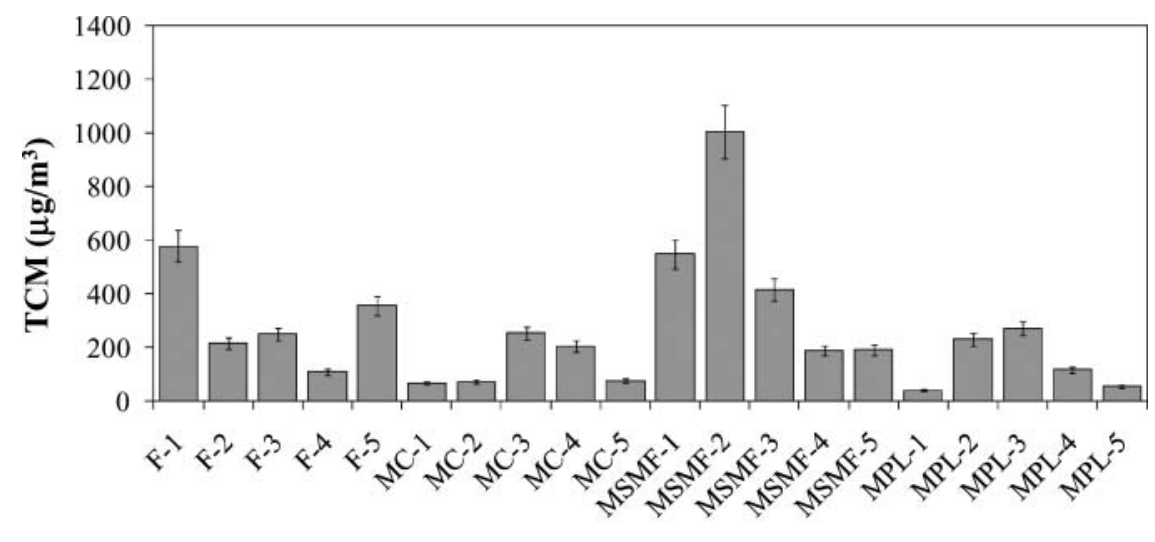

Pool and Sampling Number

Fig. 6. Mean TCM concentrations obtained in air from 4 indoor swimming pools ( $5 \mathrm{~cm}$ above water surface). 
(TWA) and NIOSH (STEL). From Figures 5 and 6 it can be seen that TCM accounts for $36 \%$ to $83 \%$ of the TTHMs.

These results confirm that inhalation is another form of exposure to THMs for users of those swimming pools.

From the overall results of this study, we may suppose that the summative effects of ingestion, absorption through skin and inhalation might be of health concern, at least in some cases. Studying and optimising swimming pools' operating conditions (air and water systems), disinfection programmes or in some cases the introduction of complementary disinfection techniques (for example using chlorine plus UV radiation) are some of the measures that may be taken to reduce the concentration of harmful DBPs. The development of expeditious analytical methods allowing easier monitoring and assessment of THMs and other DBPs in water and air from indoor swimming pools and other water leisure environments is therefore of the utmost importance. The expectable establishment in the short term of specific European regulation in this field also calls for the availability of those optimised analytical tools.

\section{Conclusions}

HS-SPME coupled with GC/ECD technique was used to determine trihalomethanes (TCM, BDCM, DBCM and TBM) in water and air from four ISPs of Northern Portugal.

In water samples analysis, high correlation coefficients were obtained in calibration lines for all THMs using a $100 \mu \mathrm{m}$ polydimethylsiloxane fiber and in the following conditions: headspace/sample volume (1.6/4.0), extraction time of $10 \mathrm{~min}$ at $55 \pm 1^{\circ} \mathrm{C}$ and desorption at $200^{\circ} \mathrm{C}$. Limits of detection were below or equal to $0.5 \mu \mathrm{g} / \mathrm{L}$ and coefficients of variation ranged from 5 to $10 \%$ and from 15 to $25 \%$ for repeatability and reproducibility, respectively.

In air samples, the analysis of THMs was achieved using a $75 \mu \mathrm{m}$ Carboxen/polydimethylsiloxane fiber in the following conditions: extraction time of $50 \mathrm{~min}$ at $30 \pm 1{ }^{\circ} \mathrm{C}$ and desorption at $200^{\circ} \mathrm{C}$. High correlation coefficients were also obtained for all calibration lines and detection limits were $2.5 \mu \mathrm{g} / \mathrm{m}^{3}$, for TCM and BDCM, and $1.25 \mu \mathrm{g} / \mathrm{m}^{3}$, for DBCM and TBM. Repeatability and reproducibility assessment in air analysis showed the same results as for water analysis.

The concentrations of THMs in water from the studied ISPs varied between $22 \pm 2$ and $577 \pm 58 \mu \mathrm{g} / \mathrm{L}$, for TTHMs and between $18 \pm 2$ and $520 \pm 52 \mu \mathrm{g} / \mathrm{L}$ for TCM. In the lack of national or European specific regulation for ISPs' water and bearing in mind that ingestion is a form of swimmers' exposure, the TTHMs concentrations were compared with drinking water quality standards. In $40 \%$ of the results the TTHMs concentration was over the European parametric value $(100 \mu \mathrm{g} / \mathrm{L})$. However the higher TTHMs concentration values found in water are not necessarily, by their own, a human health concern, taking into consideration the ratio between water involuntary ingested while swimming and total volume of water daily consumed.

The concentration of TTHMs obtained in the air samples from those 4 ISPs varied from $98 \pm 10$ to $1225 \pm 123$ $\mu \mathrm{g} / \mathrm{m}^{3}, 5 \mathrm{~cm}$ above water surface, and from $51 \pm 5$ to $906 \pm 91 \mu \mathrm{g} / \mathrm{m}^{3}, 150 \mathrm{~cm}$ above water. These data confirm that swimmers are more exposed to higher concentrations of THMs than lifeguards. As for water, there is no specific European or national regulation for THMs in the air of ISPs. So, TTHMs results were compared with the maximum value found in literature for TCM $\left(1630 \mu \mathrm{g} / \mathrm{m}^{3}\right)$ in the air of indoor swimming pools and with inhalation occupational exposure limit $\left(10,000 \mu \mathrm{g} / \mathrm{m}^{3}\right)$, established by European legislation. The analysis of THMs in air from ISPs using SPME represents a new approach among the sampling techniques already reported in the literature.

The results obtained in this study may be useful to toxicologists and rulers. Adopting very similar procedures for the analysis of THMs in water and air, as was done in the presented work, is important to save time and labour, which are usually two relevant aspects in many analytical programmes. This will be certainly the case when specific legislation becomes available and regular monitoring of THMs in swimming pools will certainly be mandatory.

\section{References}

[1] Rook, J.J. Formation of haloforms during chlorination of natural waters. J. Water Treat. Exam. 1974, 23, 234-243.

[2] WHO, Guidelines for Safe Recreational-Water Environments, Swimming Pools, Spas and Similar Recreational-Water Environments, Geneva, World Health Organization Press, 2006, 2, 146 pp.

[3] NCI, Carcinogenesis Bioassay of Chloroform; Report NTIS PB-264018; National Cancer Institute; Bethesda, MD; 1976.

[4] Chu, H.; Nieuwenhuijsen, M.J. Distribution and determinants of trihalomethane concentrations in indoor swimming pools. J. Occup. Environ. Med. 2002, 59(4), 243-247.

[5] Cammann, K.; Hubner, K. Trihalomethane concentrations in swimmers' and bath attendants' blood and urine after swimming or working in indoor swimming pools. Arch. Environ. Health 1995, 50(1), 61-65.

[6] Beech, J.A. Estimated worst case trihalomethane body burden of a child using a swimming pool. Med. Hypotheses 1980, 6(3), 303307.

[7] Faust, M. Determination of volatile brominated and chlorinated hydrocarbons in public indoor swimming-pool air (abstract only). LCGC Int. 1993, 6(7), 432-435.

[8] Aiking, H.; van Acker, M.B.; Scholten, R.J.; Feenstra, J.F.; Valkenburg, H.A. Swimming pool chlorination: a health hazard? Toxicol. Lett. 1994, 72(1-3), 375-380.

[9] Weisel, C.P.; Shepard, T.A. Chloroform exposure and the body burden associated with swimming in chlorinated pools. In Water Contamination and Health: Integration of Exposure Assessment Toxicology and Risk Assessment; R. Wang (ed.), Marcel Dekker, New York, 1994; 135-148.

[10] Aggazzotti, G.; Fantuzzi, G.; Righi, E.; Predieri, G. Environmental and biological monitoring of chloroform in indoor swimming pools. J. Chromatogr. A. 1995, 710(1), 181-190.

[11] Aggazzotti, G.; Fantuzzi, G.; Righi, E.; Predieri, G. Blood and breath analyses as biological indicators of exposure to trihalomethanes in 
indoor swimming pools. Sci. Total Environ. 1998, 217(1-2), 155163.

[12] Jovanovic, S.; Wallner, T.; Gabrio, T. Final report on the research project "Presence of Haloforms in Pool Water, Air and in Swimmers and Lifeguards in Out-Door and Indoor Pools"; Stuttgart, Landesgesundheitsamt Baden-Württemberg; 1995.

[13] Lindstrom, A.B.; Pleil, J.D.; Berkoff, D.C. Alveolar breath sampling and analysis to assess trihalomethane exposures during competitive swimming training. Environ. Health Perspect. 1997, 105(6), 636642.

[14] Stottmeister, E. Disinfection by-products in German swimming pool waters. In 2nd International Conference on Pool Water Quality and Treatment, School of Water Sciences, Cranfield University, Cranfield, UK, March 4th, 1998.

[15] Matthiessen A.; Jentsch, F. Trihalomethanes in air of indoor swimming pools and uptake by swimmers, Proceedings of ISIAQ: Indoor Air 99 Conference, Edinburgh, Scotland, August 8-13, 1999.

[16] Lahl, U.; Bätjer, K.; Duszeln, J.V.; Gabel, B.; Stachel, B.; Thiemann, W. Distribution and balance of volatile halogenated hydrocarbons in the water and air of covered swimming pools using chlorine for water disinfection. Water Res. 1981, 15(7), 803-814.

[17] Armstrong D.W.; Golden, T. Determination of distribution and concentration of trihalomethanes in aquatic recreational and therapeutic facilities by electron capture GC. LC-GC, 1986, 4, 652-655.

[18] Lévesque, B.; Ayotte, P.; LeBlanc, A.; Dewailly, E.; Prud'Homme, D.; Lavoie, R.; Allaire, S.; Levallois, P. Evaluation of dermal and respiratory chloroform exposure in humans. Environ. Health Perspect. 1994, 102(12), 1082-1087.

[19] Mannschott, P.; Erdinger, L.; Sonntag, H-P. Determination of halogenated organic compounds in swimming pool water. Zbl. Hyg. Umweltmed. 1995, 197(6), 516-533.

[20] Lévesque, B.; Ayotte, P.; Tardif, R.; Charest-Tardif, G.; Dewailly, E.; Prud'Homme, D. Evaluation of the health risk associated with exposure to chloroform in indoor swimming pools. J. Toxicol. Environ. Health A 2000, 6(4), 225-243.

[21] DIN 19643. Treatment and Disinfection of Water used in Bathing Facilities - Part 1 General Requirements, German Standard; Deutsches Institut für Normung, Berlin: Beuth Verlag, 1997.

[22] Bisted, O. Activated carbon and UV for pool water treatment. In 3rd International Conference on Pool Water Quality and Treatment; ISBN 186194 0203; School of Water Sciences, Cranfield University, England, 2002.

[23] Pawliszyn J. Solid Phase Microextraction: Theory and Practice, Wiley-VCH, New York, 1997; 264 pp.
[24] Popp, P.; Paschke, A. Solid Phase Microextraction of Volatile Organic Compounds Using Carboxen - Polydimethylsiloxane Fibers. Chromatographia. 1997, 46(7-8), 419-424.

[25] Chen, M.; Mao, I.; Hsu, C. Determination of trihalomethanes in drinking water by solid-phase microextraction and gas chromatography with electron - captured detection. Toxicol. Environ. Chem. 1997, 60(1), 39-45.

[26] Koziel, J.; Jia, M.; Khaled, A.; Noah, J.; Pawliszyn, J. Field air analysis with SPME device. Anal. Chim. Acta 1999, 400(1-3), 153162.

[27] Chai, M.; Arthur, C.L.; Pawliszyn, J.; Belardi, R.; Pratt, K. Determination of Volatile Chlorinated Hydrocarbons in Air and Water with Solid Phase Microextraction. Analyst (Cambridge, UK). 1993, 118, 1501-1505.

[28] Pavón, J.LP.; Martín, S.H.; Pinto, C.G.; Cordero, B.M. Determination of trihalomethanes in water samples: a review. Anal. Chim. Acta 2008, 23, 629(1-2), 6-23.

[29] Deok-Hee, C.; Sung-Ho, K.; Seong-Geun, O. Analysis of trihalomethanes in drinking water using headspace-SPME technique with gas chromatography. Water Res. 2003, 37(2), 402-408.

[30] Antoniou, C.V.; Koukouraki, E.E.; Diamadopoulos, E. Determination of chlorinated volatile organic compounds in water and municipal wastewater using headspace-solid phase microextraction-gas chromatography. J.Chromatogr. A 2006, 1132(1-2), 310-314.

[31] Stack, M.A.; Fitzgerald, G.; O'Connell, S.; James, K.J. Measurement of trihalomethanes in potable and recreational waters using solid phase micro extraction with gas chromatography-mass spectrometry. Chemosphere 2000, 41(11), 1821-1826.

[32] Aguilera-Herrador, E.; Lucena, R.; Cárdenas S.; Valcárcel, M.; Determination of trihalomethanes in waters by ionic liquid-based single drop microextraction/gas chromatographic/mass spectrometry. J. Chromatogr. A 2008, 1209(1-2), 76-82.

[33] Caro, J.; Gallego, M. Development of a sensitive thermal desorption method for the determination of trihalomethanes in humid ambient and alveolar air. Talanta 2008, 76(4), 847-853.

[34] Fantuzzi, G.; Righi, E.; Predieri, G.; Ceppelli, G.; Gobba, F.; Aggazzotti, G. Occupational exposure to trihalomethanes in indoor swimming pools. Sci. Total Environ. 2001, 264(3), 257-265.

[35] Peng, C.; Batterman, S. Performance evaluation of a sorbent tube sampling method using short path thermal desorption for volatile organic compounds. J. Environ. Monitor. 2000, 2(4), 313-324.

[36] Sousa, S. Implementação de uma instalação piloto para tratamento de águas contaminadas com pesticidas. MSc thesis, Faculdade de Engenharia da Universidade do Porto, Porto, Portugal, 2000. 